\title{
Evolutionary Pathways to Break Down the Resistance of Allelic Versions of the PVY Resistance Gene va
}

B. Janzac, INRA-Agrocampus Ouest-Université Rennes 1, UMR 1349 IGEPP, F-35653 Le Rheu, France; Imperial Tobacco Group, SEITA, Institut du Tabac, Domaine de la Tour, F-24100 Bergerac France; and INRA-Cirad Montpellier SupAgro, UMR 385 BGPI, Cirad TA A-54K, Campus International de Baillarguet, F-34398 Montpellier, France; M. Tribodet, INRA-Agrocampus OuestUniversité Rennes 1; C. Lacroix, INRA-Agrocampus Ouest-Université Rennes 1 and Imperial Tobacco Group, SEITA, Institut du Tabac; B. Moury, INRA, UR407 Pathologie Végétale, Domaine Saint Maurice, BP94, F-84140 Montfavet, France; J. L. Verrier, Imperial Tobacco Group, SEITA, Institut du Tabac; and E. Jacquot, INRA-Agrocampus Ouest-Université Rennes 1 and INRA-Cirad Montpellier SupAgro

\begin{abstract}
Janzac, B., Tribodet, M., Lacroix, C., Moury, B., Verrier, J. L., and Jacquot, E. 2014. Evolutionary pathways to break down the resistance of allelic versions of the PVY resistance gene va. Plant Dis. 98:1521-1529.

Emergence of viral genotypes can make control strategies based on resistance genes ineffective. A few years after the deployment of tobacco genotypes carrying alleles of the Potato virus $Y$ (PVY) recessive resistance gene $v a$, virulent $\mathrm{PVY}$ isolates have been reported, suggesting the low durability of $v a$. To have a broader view of the evolutionary processes involved in PVY adaptation to $v a$, we studied mutational pathways leading to the emergence of PVY resistance-breaking populations. The viral genome-linked protein (VPg) has been described to be potentially involved in $v a$ adaptation. Analyses of the VPg sequence of PVY isolates sampled from susceptible and resistant tobacco al-

lowed us to identify mutations in the central part of the VPg. Analysis of the virulence of wild-type isolates with known VPg sequences and of mutated versions of PVY infectious clones allowed us to (i) validate VPg as the PVY virulence factor corresponding to $v a$, (ii) highlight the fact that virulence gain in PVY occurs rapidly and preferentially by substitution at position $\mathrm{AA}_{105}$ in the $\mathrm{VPg}$, and (iii) show that the $101 \mathrm{G}$ substitution in the VPg of a PVYC isolate is responsible for cross-virulence toward two resistance sources. Moreover, it appears that the evolutionary pathway of PVY adaptation to $v a$ depends on both virus and host genetic backgrounds.
\end{abstract}

High mutation rates, short replication cycles, and high accumulation of viruses in infected tissues lead to the production of populations with polymorphic genomes. This intrapopulation diversity may allow the emergence of variants adapted to new environments. In the case of pest management for crop protection, the deployment of plant genotypes with resistance genes imposes selection pressures on viral populations that can result in the emergence of resistance-breaking isolates (34). Mechanisms of viral adaptation to plant resistance sources are well documented in the literature $(22,39)$. For numerous plant virus pathosystems, it appeared that resistance breakdown was linked to one or on a few amino acid (AA) substitutions in viral-encoded proteins. Studies on Potyvirus recessive resistance interactions showed that (i) AA substitutions in the viral genome-linked protein (VPg) are responsible for the modification of virulence of isolates $(9,20)$, (ii) the recessive resistance factor corresponds to proteins of the eukaryotic translation initiation complex, and (iii) viral infection requires interaction between the VPg and the protein encoded by the recessive resistance factor (39). The fixation of adaptive mutations in the viral genome is submitted to evolutionary forces (34). Selection and genetic drift play important roles in the evolution of viral populations submitted to resistance sources. Due to mutation/selection balance, it is expected that mutations affecting the viral fitness would be not selected. As regards the durability of resistance to

Corresponding author: E. Jacquot,

E-mail: emmanuel.jacquot@ supagro.inra.fr

* The $\boldsymbol{e}$-Xtra logo stands for "electronic extra" and indicates that a supplementary table is available online.

Accepted for publication 24 April 2014.

http://dx.doi.org/10.1094/PDIS-11-13-1126-RE

(C) 2014 The American Phytopathological Society viruses, it was observed that it varied according to the considered pathosystems $(13,19,31)$. However, it has been highlighted that both the number of mutations required for virulence gain and the evolutionary constraints acting on AA substitutions in the virus avirulence factor (19) could partially explain the observed durability of resistance genes. Consequently, the mutational pathways leading to resistance breakdown are key parameters to assess the durability of a resistance gene.

In this study, we analyzed the evolutionary pathways leading to the emergence in tobacco plants of Potato virus $Y$ (PVY) populations adapted to a recessive resistance gene. PVY is the type member of the genus Potyvirus and has a single-stranded positive-sense RNA genome of about $10 \mathrm{~kb}$ in length, with a VPg covalently attached at the $5^{\prime}$ end and a poly-A tail at its $3^{\prime}$ end. PVY has a wide host range, including cultivated Solanaceous species (e.g., potato, tomato, tobacco, and pepper), and represents one of the most economically damaging plant viruses (43). The diversity of biological, serological, and molecular characteristics of isolates of the PVY species has led to a complex classification. The first level of classification groups isolates into strains according to the host they were collected from (23). Despite the economical and agronomical impacts of PVY on tobacco production, studies of the tobacco PVY pathosystem are scarce. Tobacco strain PVY isolates have been classified on the basis of mosaic $(\mathrm{M})$ and necrotic $(\mathrm{N})$ symptoms induced on tobacco hosts known to be susceptible (S) or resistant (R) to the root-knot nematode Meloidogyne incognita (15), in three groups corresponding to $\mathrm{M}^{\mathrm{S}} \mathrm{M}^{\mathrm{R}}, \mathrm{M}^{\mathrm{S}} \mathrm{N}^{\mathrm{R}}$, and $\mathrm{N}^{\mathrm{S}} \mathrm{N}^{\mathrm{R}}$. Indeed, the necrotic response to PVY infection and the resistance to $M$. incognita were found to be pleiotropic effects of the " $R k$ " gene (41). However, this " $R k$ "-based indirect viral typing is inappropriate to describe the diversity of biological properties of PVY populations in the current agronomical context. Consequently, the PVY classification used in most of the PVY literature, including the present work, refers to potato strain isolates as the PVY potato pathosystem and has been extensively studied over the last century (8). Potato strain isolates are distributed in three main groups 
$\left(\mathrm{PVY}^{\mathrm{O}}, \mathrm{PVY}^{\mathrm{N}}\right.$, and $\mathrm{PVY}^{\mathrm{C}}$ ) on the basis of (i) their capacity to induce necrotic symptoms on Nicotiana tabacum and to overcome selected resistance genes introgressed in some Solanum tuberosum cultivars and (ii) their serological and molecular characteristics (45). Actually, phylogenetic analyses, based on sequences from PVY collected on different Solanaceous hosts (including tobacco and potato), cluster PVY isolates into the three potato strain groups, with most of the non-potato PVY isolates included in the $\mathrm{PVY}^{\mathrm{C}}$ group (33). In the present work, the classification of PVY isolates collected on tobacco fields and assigned in the $\mathrm{PVY}^{\mathrm{O}}$, $\mathrm{PVY}^{\mathrm{C}}$, and $\mathrm{PVY}^{\mathrm{N}}$ groups refers to the phylogenetic analysis carried out with a referent isolate for each group.

To limit the spread of PVY infections in fields, recessive (pvr2 ${ }^{1}$ to $\mathrm{pvr} 2^{9}$ in pepper; pot- 1 in tomato) and dominant (Pvr4 in pepper and $\mathrm{Nc}_{\mathrm{spl}}, \mathrm{Nc}_{\mathrm{tbr}}, \mathrm{Ny}_{\mathrm{tbr}}, \mathrm{Ry}_{\mathrm{adg}}$, and $\mathrm{Ry}_{\text {sto }}$ in potato) resistance sources have been described and introduced in the corresponding hosts (37). In tobacco fields, allelic forms $(0,1$, and 2$)$ of a recessive resistance gene named $v a$ (7) have been introduced in numerous cultivars of Nicotiana tabacum over the past three decades (4). The resistance encoded by $v a$ does not stop viral replication in infected cells but limits both the cell-to-cell movement of the virus in infected tissues and the expression of vein necrosis symptoms in infected tobacco leaves $(1,48)$. However, a few years after the deployment of $v a$-derived tobacco genotypes, necrotic symptoms associated with PVY infections were reported in fields grown with resistant ( $v a$-derived genotype) tobacco plants (48). Moreover, a recent survey reported the prevalence of PVY isolates adapted to $v a$ alleles in French tobacco growing areas (26). Statistical analysis revealed that this prevalence was linked to the deployment of $v a$ derived tobacco cultivars. This suggests that the selection pressure imposed by resistance to the virus has led to the emergence of resistance-breaking populations.

Because the emergence of PVY populations adapted to $v a$ resistance impairs the control strategies developed by breeders, it is important to upgrade knowledge of PVY va interactions. Previous studies on this topic have suggested that acquisition of the ability to break down the resistance conferred by the alleles $v a^{2}(2,27)$ and $v a^{0}(30)$ is associated with point mutations in the central part of the VPg. However, these data are based on comparative analysis carried out with pathotyping results obtained with PVY isolates and only a few genomic data. Actually, in these previous studies, the range of the mutational pathways for PVY virulence gain toward va resistance was not explored in large PVY populations infecting tobacco crops. To have an overview of PVY's ability to gain virulence toward different alleles of the $v a$ resistance gene, we focused on (i) the validation of the role of the VPg in the adaptation to $v a$ resistance and (ii) the exploration of the VPg mutations associated with PVY virulence on $v a$-derived tobacco genotypes. This type of information will help to predict the maintenance of virulent variants in PVY populations and their consequences on the durability of $v a$ resistance. Thus, using PVY isolates collected from susceptible and resistant tobacco cultivars in France, the genetic diversity of the VPg was first explored. Then, the genetic basis of the PVY adaptation process and the dynamic leading to the possible emergence of $v a$ resistance-breaking populations was investigated.

\section{Materials and Methods}

PVY isolates and point-mutated clones. PVY isolates used in the experiments were sampled from the PVY library constituted by Lacroix et al. in 2007 (26). This library includes 326 PVY samples collected on susceptible (VA) or resistant $(v a)$ tobacco plants in different French tobacco-growing areas (south, northeast, and northwest). Isolate names are according to Lacroix et al. (26). PVY isolates O139 (44), N605 (18), and SON41 (14), avirulent toward $v a$, were used in our biological experiments as reference isolates for $\mathrm{PVY}^{\mathrm{N}}, \mathrm{PVY}^{\mathrm{O}}$, and $\mathrm{PVY}^{\mathrm{C}}$ groups, respectively. The $\mathrm{PVY}^{\mathrm{O}}-139$ isolate belongs to a recently described (22) separate lineage of the $\mathrm{PVY}^{\mathrm{O}}$ group (i.e., $\mathrm{PVY}^{\mathrm{O} 5}$ ); however, it is widely considered as a reference isolate for the $\mathrm{PVY}^{\mathrm{O}}$ group in the literature. Thus, it has been used as the $\mathrm{PVY}^{\mathrm{O}}$ reference isolate in the present work.
Two mutated versions of the infectious cDNA clone SON41 (35), SON41_101G and SON41_119A, in which the serine at position 101 in the VPg was replaced by a glycine and the aspartic acid at position 119 was replaced by an alanine, respectively, were produced by direct site mutagenesis, as described by Ayme et al. (6). Compared with the original SON41 clone, the SON41_101G and SON41_119A clones contained, according to sequence accession number AJ439544, a single adenine-to-guanine substitution in the VPg cistron at nucleotide position 6,015 and a single adenine-tocytosine substitution in the VPg cistron at nucleotide position 6,070 , respectively.

Four mutated versions of the cDNA clone N605 (18) (i.e., N605_101G, N605_105E, N605_105T, and N605_105M) in which the serine at position 101 in the VPg was changed into a glycine and the lysine at position 105 was changed into a glutamic acid, a threonine, or a methionine, respectively, were obtained by polymerase chain reaction (PCR) mutagenesis, as previously described by Tribodet et al. (47). Compared with the original N605 clone, the N605_101G clone contained, according to sequence accession number X97895, a single adenine-to-guanine substitution in the VPg cistron at nucleotide position 6,019. Similarly, the N605_105E, N605_105T, and N605_105M clones contained an adenine-to-guanine substitution at nucleotide position 6,031 , an adenine-to-cytosine substitution at nucleotide position 6,032 , and an adenine-to-thymine substitution at nucleotide position 6,032 , respectively.

The VPg cistrons of the different mutated versions of the SON41 and N605 clones were checked to be error free before their use in biolistic inoculations. $N$. clevelandii was inoculated with the different constructions using biolistic inoculation, as described by Tribodet et al. (47). Viral progenies were detected in $N$. clevelandii 2 weeks post-inoculation by double-antibody sandwich enzymelinked immunosorbent assay (DAS-ELISA) using a polyclonal antibody kindly provided by M. Guillet [INRA-Fédération Nationale des Producteurs de Plants de Pomme de Terre, Le Rheu, France]. The VPg cistrons of the viral progenies in infected $N$. clevelandii were checked to be error free prior being used as inocula in biological characterization experiments.

Plant materials. $N$. clevelandii plants susceptible to PVY were used in biolistic inoculations to produce viruses corresponding to the original and mutated versions of the cDNA clones. Tobacco $N$. tabacum 'Xanthi' plants were used to produce viral inocula for inoculation of additional tobacco genotypes. The $N$. tabacum cultivars Xanthi and 'MN944', susceptible to PVY, carry the susceptibility allele $(V A)$ at the $v a$ locus. The three tobacco cultivars 'VAM', 'Wislica', and 'PBD6' carry the alleles 0,1 , and 2 of the $v a$ gene, respectively. Two pairs of near-isogenic lines of $N$. tabacum (i.e., Burley $\mathrm{B} V A$ and $\mathrm{B} v a^{0}$ and flue-cured $\mathrm{FVA}$ and $\mathrm{F} v a^{2}$ ), carrying the susceptibility allele $V A(\mathrm{~B} V A$ and $\mathrm{FVA})$ or alleles 0 $\left(\mathrm{B} v a^{0}\right)$ or $2\left(\mathrm{~F} v a^{2}\right)$ of the gene $v a(27)$, were used in the experiments. These different tobacco genotypes were used as susceptible or $v a$-derived resistant hosts in biological characterization experiments carried out with wild-type PVY isolates or original and mutated versions of the SON41 and N605 infectious clones. Biological assays were performed as previously described by Lacroix et al. (26).

PVY inoculation and detection. The inoculation procedure includes (i) primary inoculations of the original and mutated versions of the clones SON41 and N605 by bombardments of 5-week-old $N$. clevelandii plantlets, (ii) preparation of inocula (for PVY field isolates and clones), and (iii) mechanical inoculation of 3- to 4week-old $N$. tabacum Xanthi tobacco plants, as described by Tribodet et al. (47). Plants were grown from sowing to the end of the experiment in thermoregulated, insect-proof greenhouses with a constant temperature of $20^{\circ} \mathrm{C}$. Approximately 3 to 4 weeks after inoculation, virus was detected in plants by DAS-ELISA using a polyclonal antiserum raised against PVY, as described by Lacroix et al. (26).

Amplification of VPg cistron and sequencing. In total, 201 PVY isolates from the tobacco PVY library (26) were used to ana- 
lyze the genomic diversity of the region containing the VPg coding sequence. Total RNA extractions from PVY-infected tobacco leaves stored at $-20^{\circ} \mathrm{C}$ since the field survey were performed using the SV 96 total RNA isolation system kit (Promega Corp.). A reverse-transcription step was performed with Avian myeloblastosis virus reverse transcriptase (Promega Corp.) and the $3^{\prime}$ NTR primer (5'-GTCTCCTGATTGAAGTTTAC-3', corresponding to positions 9,701 to 9,682 of sequence $\mathrm{X} 97895$ ) according to the manufacturer's recommendations. Viral cDNAs were used to amplify the VPg cistron by PCR with the GoTaq Flexi DNA Polymerase (Promega Corp.) and primers PVY-F (5'-GGRCTYATMTAT AGTTGGTT-3', corresponding to positions 5,668 to 5,687 of sequence X97895) and PVY-R (5'-CAAACTGTTTGRGCA ATTGG-3', corresponding to positions 6,319 to 6,338 of sequence X97895). The PCR conditions were $95^{\circ} \mathrm{C}$ for $2 \mathrm{~min}$; then, 35 cycles of $95^{\circ} \mathrm{C}$ for $30 \mathrm{~s}, 52^{\circ} \mathrm{C}$ for $30 \mathrm{~s}$, and $72^{\circ} \mathrm{C}$ for $1 \mathrm{~min}$; followed by a final extension step of $72^{\circ} \mathrm{C}$ for $10 \mathrm{~min}$. Amplified fragments were sequenced by Genoscreen with the primers used for PCR. Except for the first and last 50 nucleotides of the amplified fragment, the sequences obtained were dually read (forward and reverse senses).

Phylogenetic and correspondence analyses. VPg AA sequences of the PVY isolates were aligned using the MEGA version 5 software (46). Amino acid haplotypes of PVY VPg were defined from alignments of the VPg sequences. VPg haplotypes were defined separately for isolates expected to belong to the $\mathrm{PVY}^{\mathrm{N}}$ and $\mathrm{PVY}^{\mathrm{O}}$ groups but not for isolates expected to belong to $\mathrm{PVY}^{\mathrm{C}}$ due to the low number of isolates in this group. The phylogenetic tree was constructed using the maximum likelihood method based on the JTT matrix-based model (21) in MEGA5; otherwise, BIONJ method with MCL distance matrix was used. To assess the reliability of the tree topology, analysis of 1,000 bootstrap replicates was performed. A VPg haplotype corresponds to a unique AA sequence and differs from other VPg haplotypes by at least one AA substitution. A contingence table between AA VPg haplotypes observed in PVY isolates from the tobacco field and $v a$ alleles at the $v a$ locus in the tobacco host was built with data reported in Supplementary Table S1. A $\chi^{2}$ test was first performed with the R v2.13.1 software to test the independence between the PVY VPg AA haplotypes and the corresponding $v a$ alleles in host genotypes. The association between these two variables was then tested using a correspondence analysis (CA) performed with the FactoMineR package in $\mathrm{R}$ v2.13.1. Detection of codon sites under diversifying selection in the VPg was performed with $\mathrm{dN} / \mathrm{dS}$ analysis using the SLAC method from the HyPhy software (24). Detection of AA sites under positive selection $(\mathrm{dN} / \mathrm{dS}>1)$ was performed using a threshold probability of $P=0.10$.

Biological characterization of PVY isolates. Seventeen PVY isolates collected from field-grown plants and whose consensus VPg sequences had been determined were biologically characterized using the susceptible MN944, BVA, and FVA and the resistant VAM, WISLICA, PBD6, Bva $a^{0}$ and $\mathrm{F} v a^{2}$ tobacco lines as reference hosts. Sets of 12 or 15 plants of each line were mechanically inoculated with each isolate. Approximately three to four weeks after inoculation, viruses were detected by DAS-ELISA using polyclonal antiserum raised against PVY. For each PVY isolate or clone, two infected plants per genotype were sampled (when at least two inoculated plants were infected) to perform RNA extraction and reverse-transcription (RT)-PCR amplification of the VPg cistron. The amplified fragments were sequenced. The consensus sequence of VPg associated with each infected plant was compared with the sequence of the PVY isolate or clone used as inoculum in the experiment. Modifications of AA residues in VPg sequences were analyzed. The evolutionary pathways for virulence gains were defined according to the observed AA changes in the VPg and the ability of the PVY isolates to infect resistant tobacco lines.

\section{Results}

Polymorphism of VPg in French PVY tobacco isolates. From the library of PVY tobacco isolates constituted by Lacroix et al.
(26), 201 isolates were selected for molecular characterization of their VPg sequence and phylogenetic analyses. These isolates were selected to balance distribution of geographic (north or south of France) and host (resistant or susceptible) origins. After RNA extraction and RT-PCR amplification and sequencing steps, 167 consensus sequences of the VPg coding region reached the requested quality for molecular analyses. The VPg AA sequences resulting from in silico translation of nucleotide sequences were first aligned using VPg sequences from N605, O139, and SON41 isolates as references for $\mathrm{PVY}^{\mathrm{N}}, \mathrm{PVY}^{\mathrm{O}}$, and $\mathrm{PVY}^{\mathrm{C}}$ groups, respectively. This alignment was used to (i) construct a phylogenetic tree and assign isolates in the $\mathrm{PVY}^{\mathrm{N}}$, $\mathrm{PVY}^{\mathrm{O}}$, or $\mathrm{PVY}^{\mathrm{C}}$ phylogenetic groups (according to the position in the tree of the references isolates listed above) and (ii) define VPg AA haplotypes. AA haplotypes were defined separately for isolates assigned in the $\mathrm{PVY}^{\mathrm{N}}$ and $\mathrm{PVY}^{\mathrm{O}}$ phylogenetic groups because VPg sequences of isolates belonging to these two groups were quite different (AA mean group distance $\mathrm{N} / \mathrm{O}=0.058)$. Due to the low number of VPg sequences available for isolates assigned in the $\mathrm{PVY}^{\mathrm{C}}$ group $(N=$ 4), no AA VPg haplotypes were defined for this group. Because numerous VPg sequences were redundant for isolates assigned in the $\mathrm{PVY}^{\mathrm{N}}$ and $\mathrm{PVY} \mathrm{O}^{\mathrm{O}}$ groups, AA VPg haplotypes that represent groups of isolates sharing the same VPg sequence were used for the phylogeny construction (Fig. 1). The phylogenetic analysis showed that (i) a majority of isolates infecting French tobacco crops were assigned to $\mathrm{PVY}^{\mathrm{N}}$ group $(N=134$; Fig. 1$)$ and (ii) the VPg sequences of these isolates were very close to the VPg of the PVY $^{\mathrm{N}}$-N605 reference isolate (18) initially collected on potato. This is in accordance with previous analyses of serological properties of French tobacco PVY isolates carried out by Lacroix et al. (26). About one-sixth of the sequence dataset corresponded to isolates assigned in the $\mathrm{PVY}^{\mathrm{O}}$ group $(N=29)$ and only four isolates from the analyzed PVY library were assigned to the $\mathrm{PVY}^{\mathrm{C}}$ group (Fig. 1). We also observed that the genetic polymorphism of the VPg in the PVY ${ }^{\mathrm{N}}$ phylogenetic group is low $(N=134$, average $P$ distance $=0.007)$ and slightly higher in the $\mathrm{PVY}^{\mathrm{O}}$ group $(N=29$, average $P$ distance $=0.009)$. The analysis of the $163 \mathrm{VPg}$ sequences of isolates assigned in the $\mathrm{PVY}^{\mathrm{N}}$ and $\mathrm{PVY} \mathrm{O}^{\mathrm{O}}$ groups allowed us to define 18 and $13 \mathrm{VPg}$ AA haplotypes, respectively (Fig. 1). The $18 \mathrm{PVY}^{\mathrm{N}}$-type VPg AA sequences were distributed in two main $\left(\mathrm{A}^{\mathrm{N}}, N=51\right.$ and $\left.\mathrm{B}^{\mathrm{N}}, N=44\right)$, seven intermediate $\left(\mathrm{C}^{\mathrm{N}}\right.$ to $\mathrm{I}^{\mathrm{N}}, N=8$ to 2 ), and nine "orphan" (i.e., represented by a unique isolate, $\mathrm{J}^{\mathrm{N}}$ to $\mathrm{R}^{\mathrm{N}}$ ) haplotypes. For isolates assigned in the $\mathrm{PVY} \mathrm{O}^{\mathrm{O}}$ group, VPg AA sequences were distributed in one main $\left(\mathrm{A}^{\mathrm{O}}, N=\right.$ $13)$, three intermediate $\left(\mathrm{B}^{\mathrm{O}}\right.$ to $\mathrm{D}^{\mathrm{O}}, N=3$ to 2$)$, and nine orphan $\left(\mathrm{E}^{\mathrm{O}}\right.$ to $\mathrm{M}^{\mathrm{O}}$ ) haplotypes.

Although the presented phylogeny was obtained with VPg sequences of isolates from susceptible and resistant tobacco genotypes, the clustering of isolates observed in the phylogenetic tree did not explain PVY virulence properties toward $v a$ (Fig. 1). Likewise, the tree topology was not supported by geographical origins of the isolates (data not shown).

To test a potential link between the PVY VPg AA haplotypes and the susceptible $(V A)$ or $v a$ resistance alleles present in the corresponding sampled tobacco host, a $\chi^{2}$ test of independence was run. The $\chi^{2}$ tests indicated, for both PVY ${ }^{\mathrm{N}}$-type $\left(\chi^{2}=154.9116\right.$, df $=34, P$ value $<2.2 \mathrm{e}-16)$ and $\mathrm{PVY}^{\mathrm{O}}$-type $\left(\chi^{2}=29 \mathrm{df}=12, P\right.$ value $=0.003)$ data, that the tested variables were not independent. To specify the links between these two variables, a CA was used. The first axis of the CA factor map clearly separates data associated to "susceptibility allele" from those associated to "resistant alleles" at the $v a$ locus. The CA factor map highlighted the association between some $\mathrm{PVY}^{\mathrm{N}}$-type VPg haplotypes and the host genotypes categorized as "susceptible" (i.e., VA) or "resistant" (i.e., va or $v a^{2}$ ) (Fig. 2). Indeed, $79.8 \%$ of $\mathrm{PVY}^{\mathrm{N}}$-type $\mathrm{VPg}$ haplotype distribution is explained by the first axis. The values close to 1 reflect a dichotomy of the data and indicate a significant correlation between viral- and host-tested parameters. The CA factor map also suggests that some VPg AA haplotypes $\left(\mathrm{B}^{\mathrm{N}}, \mathrm{C}^{\mathrm{N}}\right.$, and $\mathrm{H}^{\mathrm{N}}$ ) allowed adaptation to $v a^{0}$ and $v a^{2}$. For PVY $\mathrm{O}^{\mathrm{O}}$-type VPg 
haplotypes, the CA could not be performed due to the presence of only one $v a$-resistant allele $\left(v a^{0}\right)$ in the dataset.

Codon positions under selection in the VPg and analysis of AA substitutions. Detection of codon sites under selection was performed using a dN/dS approach. This analysis, carried out on the whole VPg sequences, showed a mean $\mathrm{dN} / \mathrm{dS}$ value of 0.118 and allowed us to detect 1 of the 188 codons of the PVY VPg sequence under diversifying (positive) selection $(\mathrm{dN} / \mathrm{dS}>1)$ and 47 negatively selected codons $(\mathrm{dN} / \mathrm{dS}<1)$. The codon under diversifying selection $\left(\mathrm{dN} / \mathrm{dS}=5.78, P\right.$ value $\left.=7.8810^{-4}\right)$ is located at position 105 in the VPg coding sequence. All the isolates collected from susceptible tobacco genotypes have a lysine $(\mathrm{K})$ at position 105 in their VPg whereas up to seven different residues were observed at this position for isolates collected from resistant tobacco plants (Fig. 3). However, about 25\% (19/82 and 3/12 for $\mathrm{PVY}^{\mathrm{N}}$ and
$\mathrm{PVY}^{\mathrm{O}}$ groups, respectively) of PVY isolates collected on resistant tobacco hosts code for a $K_{105}$ in their VPg. Because $K_{105}$ was strictly conserved in the VPg sequence of isolates collected on susceptible tobacco genotypes, this result provides evidence that positions other than codon 105 in the VPg can be also involved in PVY adaptation to $v a$.

Biological characterization of PVY isolates with known VPg sequences. Because the AA substitution analysis highlighted the observation that position 105 in the VPg of isolates assigned to $\mathrm{PVY}^{\mathrm{N}}$ and $\mathrm{PVY}^{\mathrm{O}}$ groups seems to be involved in $v a$ adaptation, PVY isolates representing main PVY VPg haplotypes collected in tobacco fields were characterized for their virulence toward $v a$. Thus, the biological properties of four and eight isolates assigned in the $\mathrm{PVY}^{\mathrm{N}}$ group and of one and four isolates assigned in the $\mathrm{PVY}^{\mathrm{O}}$ group, from susceptible and resistant tobacco genotypes,

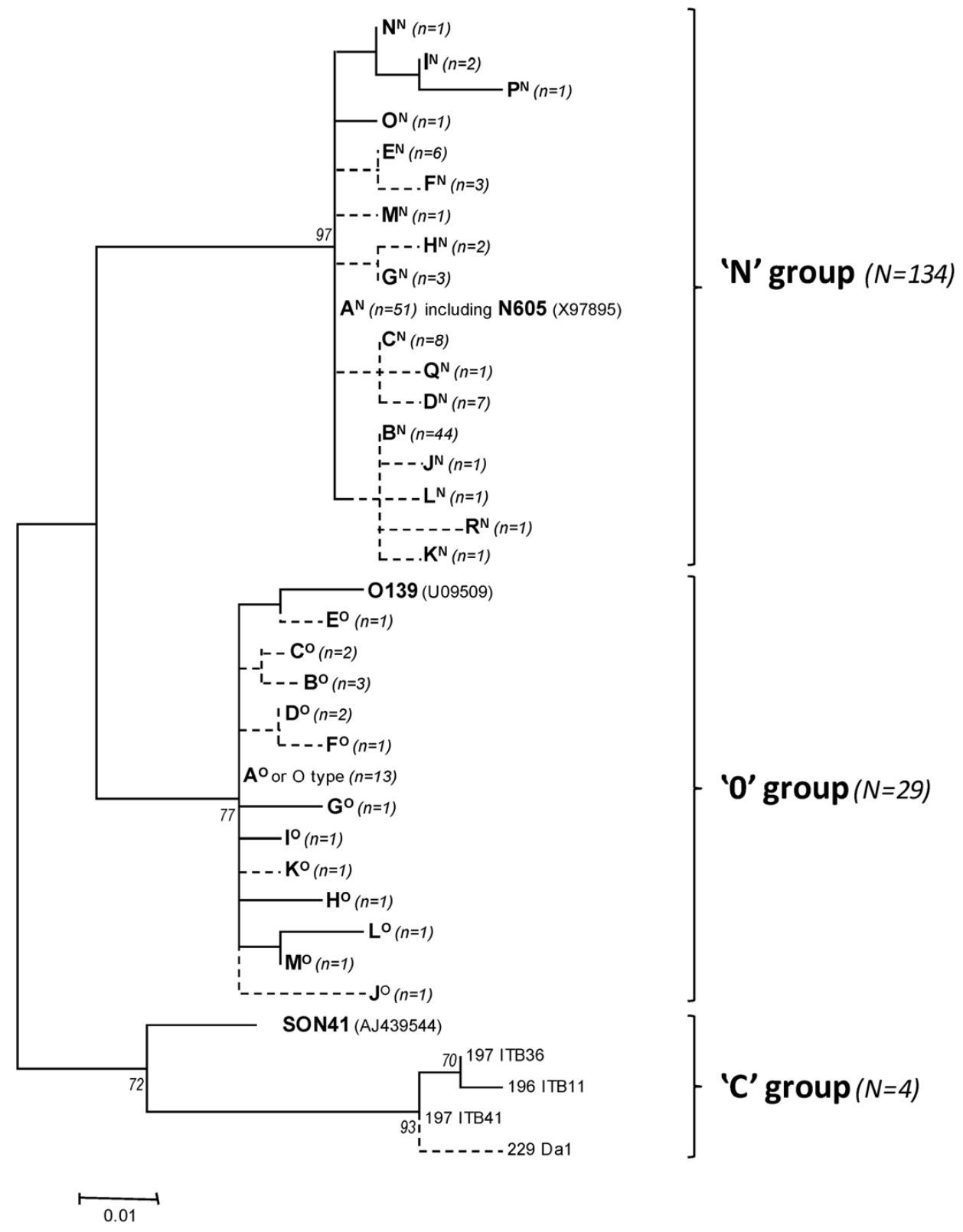

Fig. 1. Phylogenetic tree (maximum likelihood method) obtained from the alignment of viral genome-linked protein (VPg) amino acid (AA) sequences of 167 Potato virus $Y$ (PVY) tobacco isolates collected in French tobacco crops in 2007. The maximum likelihood method is based on the JTT matrix-based model (21) in MEGA5; BIONJ method with $M C L$ distance matrix was used. VPg AA haplotypes $\left(A^{N}\right.$ to $R^{N}$ and $A^{0}$ to $\left.M^{0}\right)$ were analyzed instead of all individual $P V Y$ isolates to remove redundant sequences. Continuous and discontinuous lines indicate VPg haplotypes from isolates collected on susceptible and resistant tobacco genotypes, respectively. Numbers between brackets after haplotype names indicate the total number of isolates grouped in the corresponding haplotype. "O type" is for PVY isolates having their VPg AA sequence identical to the published sequence accession number U09509 only between the AA residues 60 to 175 . Bootstrap percentages over $70 \%$ are reported. PVY clusters N, O, and C were determined according to VPg sequence of reference isolates N605, 0139, and SON41, respectively. The tree is drawn to scale, with branch lengths measured in the number of substitutions per site. 
respectively, were determined using four different tobacco lines carrying susceptibility or resistance $v a$ alleles (Table 1). Comparison of VPg sequences from the inocula and from the viral progenies infecting resistant tobacco plants provided information on AA substitutions required to infect resistant genotypes. Results revealed that isolates with VPg haplotype $\mathrm{A}^{\mathrm{N}}$ (i.e., identical to the avirulent N605 isolate) acquire at least one AA substitution to infect $v a$-derived genotypes. VPg sequence comparisons also revealed the occurrence of a preferential substitution at position 105 in the VPg, including substitution of the lysine $105 \mathrm{~K}$ by a glutamic acid (105E; 14/19), a methionine (105M; 3/19), a threonine (105T; $1 / 19)$, or a glutamine (105Q; 1/19). Isolates belonging to haplotypes $\mathrm{B}^{\mathrm{N}}$ and $\mathrm{C}^{\mathrm{N}}$, with a single substitution at position $105(105 \mathrm{E}$ or $105 \mathrm{~T}$, respectively) compared with haplotype $\mathrm{A}^{\mathrm{N}}$, were able to infect $v a$ genotypes without additional mutation in their VPg sequence. As suggested by the analysis of the AA residues at position 105 in PVY isolates from resistant tobacco, alternative pathways for $v a$ adaptation (not involving the VPg residue 105) exist, as shown by isolate $222 \mathrm{Sav} 4$ from susceptible tobacco that seemed to adapt to $v a^{2}$ through mutations at positions 101 (101G, glycine) and 108 (108I, isoleucine). However, an isolate of haplotype $\mathrm{E}^{\mathrm{N}}$,

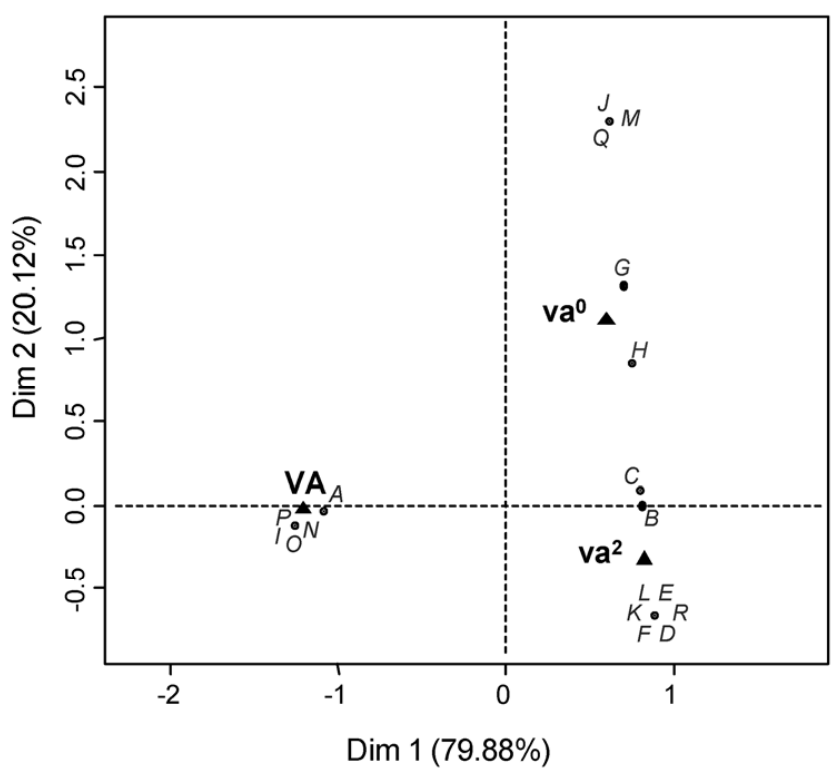

Fig. 2. Map factor of the correspondence analysis performed between viral genome-linked protein (VPg) amino acid haplotypes in the Potato virus $Y(P V Y)^{\mathrm{N}}$ group and va alleles in sampled tobacco hosts (resistance alleles $v a^{0}$ and $v a^{2}$ and susceptibility allele VA). Dim 1 and $\operatorname{Dim} 2$ axes explain a percentage of data variation (VPg haplotypes). Dim 1 explains $79.88 \%$ of VPg haplotype variation and that VPg haplotypes clustered according to va alleles. Uppercase letters in normal font correspond to VPg amino acid haplotypes defined in this work. differing from haplotype $\mathrm{A}^{\mathrm{N}}$ by a $101 \mathrm{G}$ mutation, was not able to infect $v a$-resistant genotypes without accumulating at least one extra mutation in the VPg. Infectivity of isolates belonging to haplotypes $\mathrm{G}^{\mathrm{N}}$ or $\mathrm{F}^{\mathrm{N}}$ depended on the resistance allele present at the $v a$ locus. Thus, additional VPg AA substitutions seemed to be required by these isolates but only to infect some of the tested $v a$ resistant genotypes.

Analyses performed with isolates assigned in the $\mathrm{PVY}^{\mathrm{O}}$ group showed that a glutamic acid (E) or a methionine (M) at position 105 in the VPg conferred the ability to infect tobacco hosts with $v a$ resistance alleles without the requirement of additional mutations. An arginine ( $\mathrm{R})$ at this position seemed to confer adaptation to tobacco genotypes carrying $v a^{l}$ or $v a^{2}$ but only partial adaptation to $v a^{0}$ (only 7/12 of the VAM plant infected; sequence data of the progeny not available). Isolates with a haplotype containing a lysine at position $105(105 \mathrm{~K})$ (e.g., the isolate O139) require substitutions at positions 105 or 101 to infect some of the tested $v a$-resistant genotypes. An isolate with a tyrosine $(\mathrm{Y})$ at position 121 (isolate $259661 \mathrm{MLe1}$ ) was able to infect tobacco genotypes with $v a^{l}$ and $v a^{2}$ alleles without the need of additional mutations but was unable to efficiently infect $v a^{0}$ plants. An isoleucine at position 77 of the VPg of an isolate assigned in the $\mathrm{PVY}^{\mathrm{O}}$ group seemed to confer adaptation to $v a^{l}$ but not to $v a^{0}$ or $v a^{2}$ (isolate 214 31612Csa8).

Finally, preliminary analyses of the sequence of viral progenies in susceptible (VA) tobacco lines showed that the 105E residue conferring virulence toward $v a$ alleles reverted to $105 \mathrm{~K}$, as illustrated by the detection of a $105 \mathrm{~K} / 105 \mathrm{E}$ mixture in the PVY populations infecting MN944 plants inoculated with the 273Ter4 or 288Cug2 isolates.

Validation of the role of VPg AA mutations in PVY adaptation to va. Analysis of the selection signature in the VPg sequence data set highlighted the observation that position 105 was possibly involved in PVY adaptation to va. However, the analysis of the AA substitutions in the VPg of viral progenies of some isolates able to infect resistant tobacco plants showed that, in addition to position 105 , other substitutions at different positions in the VPg sequence allowed adaptation to $v a$. Thus, a reverse-genetics approach was used to validate the role of some VPg residues on the breakdown of $v a$ resistance. Four mutated versions of the infectious cDNA clone N605 were created. According to results obtained by Lacroix et al. (27), two mutated versions of the $\mathrm{PVY}^{\mathrm{C}}$ infectious cDNA clone SON41 were also constructed. Each of these mutants carries a single-nucleotide substitution in the VPg coding sequence. The biological properties of these PVY mutants were characterized using inoculation experiments carried out on both susceptible and resistant tobacco genotypes.

In resistant tobacco plants, the N605_101G mutant accumulated additional VPg mutations compared with the inoculum, suggesting that the $S$ to $G$ substitution at position 101 in the VPg of N605 does not correspond to a virulent VPg haplotype toward $v a$
$\mathrm{Y}^{\mathrm{N}}$ isolates $(\mathrm{N}=\mathbf{8 2})$

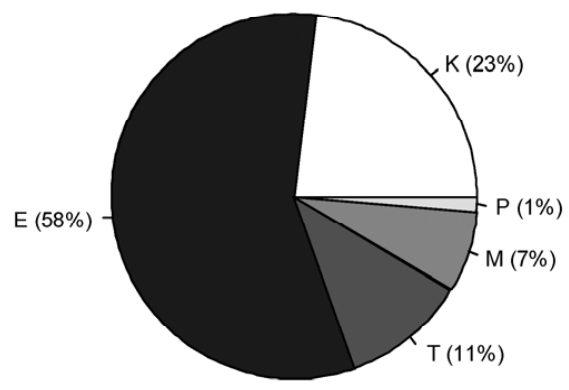

$\mathrm{Y}^{\mathrm{O}}$ isolates $(\mathrm{N}=16)$

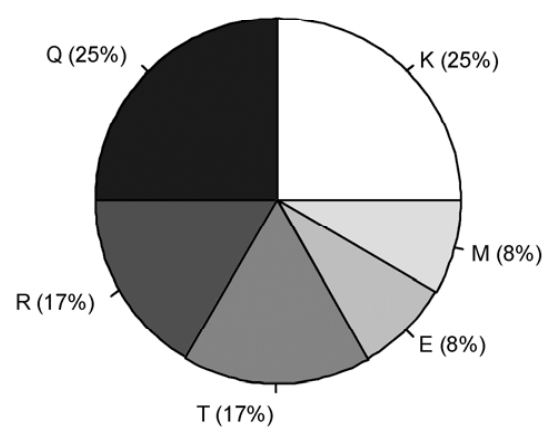

Fig. 3. Amino acid (AA) residues observed at position 105 in the viral genome-linked protein $(\mathrm{VPg})$ of $P$ otato virus $Y(P V Y)^{\mathrm{N}}$ and $P V Y O$ isolates from resistant tobacco plants. $A A$ residues are presented with the one-letter codes $K=$ lysine, $E=$ glutamic acid, $T=$ threonine, $M=$ methionine, $P=$ proline, $Q=$ glutamine, and $R=$ arginine. 
resistance (Table 2). However, similar analysis performed for N605_105E, N605_105T, or N605_105M mutants showed no additional mutation in the $\mathrm{VPg}$ of the progenies produced in resistant tobacco plants. Therefore, the $\mathrm{K}$ to $\mathrm{E}$, $\mathrm{T}$, or $\mathrm{M}$ substitutions at position 105 in the VPg of N605 confer to PVY the capacity to infect tobacco genotypes carrying the resistance alleles $v a^{0}, v a^{1}$, and $v a^{2}$. In accordance with previous results (27), the $\mathrm{S}$ to $\mathrm{G}$ and $\mathrm{D}$ to A substitutions at positions 101 and 119 , respectively, in the VPg of SON41 seem sufficient to allow infection of $v a^{l}$ and $v a^{2}$ tobacco genotypes. However, these substitutions were not sufficient to confer virulence toward the $v a^{0}$ resistance allele.

\section{Discussion}

To evaluate the adaptive potential of PVY isolates and the mutational pathways involved in the breakdown of the $v a$ resistance gene, we first explored the molecular diversity of PVY isolates from tobacco fields. Then, we designed experimental procedures to study the processes leading to emergence of virulent populations toward $v a$ alleles.

Masuta et al. (30), Lacroix et al. (27), and Acosta-Leal and Xiong (2) have suggested that AA modifications in VPg were in- volved in PVY adaptive response to $v a$ resistance. Here, the analysis of the relation between (i) the genetic diversity of the VPg AA haplotypes of isolates and (ii) the presence of $v a$ alleles in the tobacco hosts indicated a clear link between this two traits. Moreover, this analysis suggested that an AA VPg haplotype could confer virulence to both $v a^{0}$ and $v a^{2}$. However, we observed that some isolates collected from susceptible tobacco and biologically assigned to pathotype $0-1-2$ by Lacroix et al. (26) encode a VPg AA haplotype related to avirulence properties toward $v a$. If we consider that PVY populations evolved rapidly to adapt to $v a$, the contradictory results described above could fit together. Actually, biological characterization experiments showed that virulence toward $v a$ could be acquired after either the infection of a single resistant host (Table 2) (27) or a subsequent inoculation (passage) of the emerging variant on a resistant host, as described by Acosta-Leal and Xiong (2).

Such a rapid adaptation to a resistance source has already been demonstrated in serial passage experiments for different plant viruses, in which resistance-breaking variants were obtained after a few passages (10).

In many cases, virus adaptation to plant resistance depends on one or on a few nucleotide or residue substitutions in the viral avir-

Table 1. Biological properties of Potato virus $Y(\mathrm{PVY})$ isolates with known viral genome-linked protein (VPg) sequences

\begin{tabular}{|c|c|c|c|c|c|c|c|c|c|c|c|c|c|}
\hline \multirow[b]{3}{*}{ Isolate $^{\mathrm{b}}$} & \multirow{2}{*}{\multicolumn{2}{|c|}{ Origin }} & \multirow[b]{3}{*}{ Group $^{\text {d }}$} & \multirow[b]{3}{*}{ Sequence $^{\mathrm{e}}$} & \multirow[b]{3}{*}{ Hap $^{f}$} & \multicolumn{8}{|c|}{ Tobacco genotypes and VPg sequences ${ }^{a}$} \\
\hline & & & & & & \multicolumn{2}{|c|}{ MN944 (VA) } & \multicolumn{2}{|c|}{$\operatorname{VAM}\left(v a^{0}\right)$} & \multicolumn{2}{|c|}{ WISLICA $\left(v a^{I}\right)$} & \multicolumn{2}{|c|}{ PBD6 $\left(v a^{2}\right)$} \\
\hline & Area & Host $^{\mathrm{c}}$ & & & & Inf. & VPg & Inf. & VPg & Inf. & VPg & Inf. & VPg \\
\hline N605 * & Switzerland & Potato & $\mathrm{N}$ & N605 & $\mathrm{A}^{\mathrm{N}}$ & 11 & None & 0 & $\ldots$ & 5 & $\begin{array}{l}105 \mathrm{E} \\
105 \mathrm{E}\end{array}$ & 1 & $105 \mathrm{E}$ \\
\hline $\mathrm{O} 139 *$ & Canada & Potato & $\mathrm{O}$ & O139 & nd & 12 & None & 0 & $\ldots$ & 4 & $\begin{array}{r}105 \mathrm{Q} \\
105 \mathrm{Q}\end{array}$ & 4 & 101G; nd \\
\hline $225 \mathrm{Fa} 2$ & South & $S$ & $\mathrm{~N}$ & N605 & $\mathrm{A}^{\mathrm{N}}$ & 12 & None & 0 & $\ldots$ & 3 & $\begin{array}{c}105 \mathrm{E} \\
105 \mathrm{M}\end{array}$ & 5 & $105 \mathrm{E} ; 105 \mathrm{E}$ \\
\hline 222 Sav4 & South & S & $\mathrm{N}$ & N605 & $\mathrm{A}^{\mathrm{N}}$ & 12 & None & 2 & $\begin{array}{r}105 \mathrm{E} \\
105 \mathrm{E}\end{array}$ & 9 & $\begin{array}{c}105 \mathrm{E} \\
105 \mathrm{M}\end{array}$ & 6 & $\begin{array}{l}101 \mathrm{G}+ \\
108 \mathrm{I} ; 105 \mathrm{E}\end{array}$ \\
\hline $224 \mathrm{Mi}$ & South & S & $\mathrm{N}$ & N605 & $\mathrm{A}^{\mathrm{N}}$ & 12 & None & 1 & $105 \mathrm{E}$ & 10 & 105T; nd & 9 & $105 \mathrm{Q} ; 105 \mathrm{E}$ \\
\hline $226 \mathrm{~K} 171 \mathrm{Fa} 3$ & South & $S$ & $\mathrm{~N}$ & N605 & $\mathrm{A}^{\mathrm{N}}$ & 12 & None & 0 & $\ldots$ & 2 & $\begin{array}{l}105 \mathrm{M} \\
105 \mathrm{E}\end{array}$ & 1 & $105 \mathrm{E}$ \\
\hline $269 \operatorname{Csh} 2$ & Northwest & $\mathrm{F} v a^{2}$ & $\mathrm{~N}$ & $\mathrm{~N} 605+101 \mathrm{G}$ & $E^{N}$ & 12 & None & 12 & $\begin{array}{r}105 \mathrm{E} \\
105 \mathrm{E}\end{array}$ & 12 & $\begin{array}{c}105 \mathrm{~T} \\
108 \mathrm{I}\end{array}$ & 11 & $\begin{array}{l}105 \mathrm{~N}+ \\
108 \mathrm{I} ; 108 \mathrm{I}\end{array}$ \\
\hline $287 \mathrm{Ssl3}$ & Northwest & $\mathrm{F} v a^{2}$ & $\mathrm{~N}$ & $\begin{array}{l}\text { N605 + 101G } \\
+108 \mathrm{I}\end{array}$ & $\mathrm{F}^{\mathrm{N}}$ & 12 & $\begin{array}{r}101 \mathrm{G}+101 \mathrm{~S} \\
101 \mathrm{G}+101 \mathrm{~S}\end{array}$ & 8 & None & 12 & $\begin{array}{r}119 \mathrm{D} ; \\
119 \mathrm{D}\end{array}$ & 12 & 119D; 119D \\
\hline 255 667Lap1 & Northeast & $\mathrm{F} v a^{2}$ & $\mathrm{~N}$ & $\mathrm{~N} 605+105 \mathrm{E}$ & $\mathrm{B}^{\mathrm{N}}$ & 12 & None & 12 & None & 12 & None & 12 & None \\
\hline 273273 Ter 4 & Northwest & $\mathrm{F} v a^{2}$ & $\mathrm{~N}$ & $\mathrm{~N} 605+105 \mathrm{E}$ & $B^{N}$ & 12 & $\begin{array}{r}105 \mathrm{E}+105 \mathrm{~K} \\
105 \mathrm{E}+105 \mathrm{~K}\end{array}$ & 12 & None & 11 & None & 12 & None \\
\hline $288 \mathrm{Cug} 2$ & Northwest & $\mathrm{F} v a^{2}$ & $\mathrm{~N}$ & $\mathrm{~N} 605+105 \mathrm{E}$ & $B^{N}$ & 12 & $\begin{array}{l}119 \mathrm{R} ; 105 \mathrm{E}+ \\
105 \mathrm{~K}\end{array}$ & 12 & None & 12 & None & 12 & None \\
\hline 287 Ss14 & Northwest & $\mathrm{F} v a^{2}$ & $\mathrm{~N}$ & $\mathrm{~N} 605+105 \mathrm{~T}$ & $\mathrm{C}^{\mathrm{N}}$ & 12 & None & 12 & None & 12 & None & 12 & None \\
\hline 286 Cor 2 & Northwest & $\mathrm{B} v a^{0}$ & $\mathrm{~N}$ & $\mathrm{~N} 605+109 \mathrm{D}$ & $\mathrm{G}^{\mathrm{N}}$ & 11 & None & 11 & None & 12 & $\begin{array}{r}105 \mathrm{~N} \\
101 \mathrm{G}\end{array}$ & 11 & None \\
\hline 209 209TH8 & South & $\mathrm{B} v a^{0}$ & $\mathrm{~N}$ & N605 + 109D & $G^{N}$ & 12 & None & 12 & $\begin{array}{r}105 \mathrm{~N} \\
101 \mathrm{G}\end{array}$ & 8 & $\begin{array}{l}108 \mathrm{I} \\
108 \mathrm{I}\end{array}$ & 12 & $105 \mathrm{~N} ; 105 \mathrm{~N}$ \\
\hline 21431612 Csa8 & South & $\mathrm{S}$ & $\mathrm{O}$ & O type $+77 \mathrm{I}$ & $\mathrm{A}^{\mathrm{O}}$ & 12 & None & 0 & $\ldots$ & 12 & None & 5 & 105T; nd \\
\hline $256623 \mathrm{Nlc} 5$ & Northeast & $\mathrm{F} v a^{2}$ & $\mathrm{O}$ & O type $+105 R$ & $\mathrm{C}^{\mathrm{O}}$ & 12 & None & 7 & nd & 12 & None & 12 & None \\
\hline 25930804 MLe4 & Northeast & $\mathrm{F} v a^{2}$ & $\mathrm{O}$ & O type $+105 E$ & $\mathrm{E}^{\mathrm{O}}$ & 12 & None & 9 & None & 12 & None & 12 & None \\
\hline 255661 Lap4 & Northeast & $\mathrm{F} v a^{2}$ & $\mathrm{O}$ & O type $+105 \mathrm{M}$ & $\mathrm{F}^{\mathrm{O}}$ & 12 & None & 12 & None & 12 & None & 12 & None \\
\hline 259661 MLe1 & Northeast & $\mathrm{F} v a^{2}$ & $\mathrm{O}$ & O type $+121 Y$ & $\mathrm{~K}^{\mathrm{O}}$ & 12 & None & 1 & nd & 11 & None & 12 & None \\
\hline
\end{tabular}

a Tobacco genotypes used for biological characterization: MN944 = susceptible host and VAM, Wislica, and PBD6 = PVY-resistant host phenotypes carrying the $v a$ resistance alleles 0,1 , and 2, respectively (26). Inf. = total number of infected plants out of the 12 inoculated tobacco plants. PVY detection assessed by double-antibody sandwich enzyme-linked immunosorbent assay with polyclonal anti-serum at 3 to 4 weeks after inoculation. VPg $=\mathrm{VPg}$ mutations in progenies: AA variations between the VPg sequences of the progenies present in randomly chosen infected plants (one or two plants) and the sequence of inoculated PVY isolate. AA residues are presented with the one letter code $\mathrm{G}=$ glycine, $\mathrm{I}=$ isoleucine, $\mathrm{E}=$ glutamic acid, $\mathrm{T}=$ tyrosine, $\mathrm{M}=$ methionine, $\mathrm{D}$ $=$ aspartic acid, $\mathrm{R}=$ arginine, $\mathrm{S}=$ serine, $\mathrm{K}=$ lysine, $\mathrm{Q}=$ glutamine, and $\mathrm{N}=$ asparagine. AA variations observed in the $\mathrm{VPg}$ of viral progenies from each of the two infected plants are listed and separated by a semicolon; "+" indicates multiple AA variations in a progeny from an infected plant. None $=$ no additional amino acid (AA) substitutions and nd = not determined.

${ }^{\mathrm{b}}$ Asterisk (*) indicates reference isolates.

${ }^{\mathrm{c}} \mathrm{S}=$ susceptible tobacco cultivars, $\mathrm{B} v a^{0}=$ burley resistant tobacco cultivars carrying the $v a^{0}$ resistant allele, and Fva $a^{2}$ flue cured resistant tobacco cultivars carrying the $v a^{2}$ resistance allele (26).

d Phylogenetic group.

e VPg sequence in inoculum. "N605" is mentioned for PVY isolates having their entire VPg AA sequence identical to accession number X97895, except for the reported AA residues; "O type" is mentioned for PVY isolates having their VPg AA sequence identical to accession number U09509 (between the AA residues 60 to 175 only). AA residues are presented with the one letter code: $\mathrm{G}=$ glycine, $\mathrm{I}=$ isoleucine, $\mathrm{E}=$ glutamic acid, $\mathrm{T}=\mathrm{threonine}, \mathrm{D}=$ aspartic acid, $\mathrm{R}=$ arginine, $\mathrm{M}=$ methionine, and $\mathrm{Y}=$ tyrosine .

${ }^{\mathrm{f}}$ VPg AA haplotypes defined in this work. 
ulence factor (33). Comparison of VPg sequences between PVY avirulent isolates and the corresponding virulent progenies highlighted the fact that PVY can evolve and adapt to the different $v a$ alleles through the acquisition of nonsynonymous mutations in the VPg cistron (Fig. 4). The large PVY library used in this study made possible the description, within and between PVY groups, of several mutational pathways based on AA substitutions at positions $101,105,108$, or 109 of the VPg. Nevertheless, adaptive substitutions observed in VPg of isolates were preferentially selected and fixed at $\mathrm{AA}$ position 105 (i.e., haplotypes $\mathrm{B}^{\mathrm{N}}$ to $\mathrm{D}^{\mathrm{N}}$ and $\mathrm{B}^{\mathrm{O}}$ to $\mathrm{E}^{\mathrm{O}}$ ), a position under diversifying selection. The involvement of $\mathrm{VPg}$ residue 105 in the virulence gains toward $v a$ resistance was confirmed using site-directed mutants of an avirulent PVY ${ }^{\mathrm{N}}$ cDNA clone. The resulting data proved that the PVY VPg is the virulence factor corresponding to the tobacco $v a$ gene. Most of the observed $\mathrm{AA}_{105}$ variations correspond to a $\mathrm{K}$ to $\mathrm{E}$ change but alternative substitutions were also observed (e.g., $\mathrm{K}$ to $\mathrm{M}$ or $\mathrm{K}$ to $\mathrm{T}$ ). Analysis of VPg sequences of both avirulent and virulent isolates showed that a single-nucleotide mutation is associated with each AA substitution described to be involved in PVY $v a$ adaptation. However, the $\mathrm{K}$ to $\mathrm{E}$ adaptive substitution corresponds to a transition whereas the other listed mutations correspond to transversions. Transitions were described to be more frequent in sequence mutations than transversions and could partially explain the unbalanced distribution of $\mathrm{AA}_{105}$ residues in resistance-breaking PVY populations from fields. Nevertheless, genetic drift and selection effects should be taken into account to broadly explain the distribution of these adaptive mutations in resistance-breaking populations. Thus, analysis of fitness cost imposed by each adaptive substitution should be explored to determine possible synergist or antagonist consequences on the rates of the different $\mathrm{AA}$ in the VPg sequence of natural PVY populations.

Although we proved that mutational pathways for virulence gain involved substitution at position 105 in the VPg sequence in about $75 \%$ of the resistance-breaking isolates, it appeared that the remaining $25 \%$ of isolates exploit other evolutionary pathways to gain virulence toward $v a$. Analysis of the $v a$-virulent populations obtained under controlled conditions suggested that VPg residues 101, 108, or 109 in $\mathrm{PVY}^{\mathrm{N}}$-type genetic background and residue 121 in $\mathrm{PVY}^{\mathrm{O}}$-type genetic background are involved in va adaptation. Similarly, the analysis of the virulence of the point-mutated clones SON41_101G and SON41_119A highlighted the impact of these two mutations on the $\mathrm{PVY}^{\mathrm{C}}$ virulence toward $v a^{2}$. However, it appears that, depending on both virus and host genetic backgrounds, these AA substitutions correlate or not with virulence

A

\begin{tabular}{|c|c|c|c|}
\hline $\begin{array}{l}\text { Avirulent } \\
\text { markers }\end{array}$ & K & V & $E$ \\
\hline $\begin{array}{l}\begin{array}{c}\text { Position in VPg } \\
\text { sequence }\end{array} \\
10\end{array}$ & $\underset{105}{1}$ & $\stackrel{1}{108}$ & $\begin{array}{c}1 \\
109 \\
1\end{array}$ \\
\hline $\begin{array}{l}\text { Virulent } \\
\text { markers }\end{array}$ & $\begin{array}{c}E / T \\
M / N / Q\end{array}$ & I & $\mathrm{D} / \mathrm{N}$ \\
\hline
\end{tabular}

B

\begin{tabular}{l|ll}
\cline { 2 - 3 } AA positions in $\mathrm{Y}^{\mathrm{N}}$ & Position(s) & Virulencegain \\
\cline { 2 - 3 } isolates involved in & 105 & $v a^{0,1,2}$ \\
resistance breaking & $101+108$ & $v a^{0,1,2}$ \\
& 109 & $v a^{0,2}$ \\
& $101+109$ & $v a^{1}$ \\
& $108+109$ & $v a^{1}$
\end{tabular}

Fig. 4. Simplified amino acid mutational pathways in the viral genome-linked protein $(\mathrm{VPg})$ of Potato virus $Y(\mathrm{PVY})^{\mathrm{N}}$ isolates to gain virulence toward va alleles. Numbers correspond to amino acid (AA) positions in the VPg of PVY. A, Above the lines are reported $A A$ residues at positions in the VPg sequence of the avirulent reference isolate N605 (AA one-letter codes $\mathrm{G}=$ glycine, $\mathrm{S}=$ serine, $\mathrm{K}=$ lysine, $\mathrm{E}=$ glutamic acid, $T=$ threonine, $M=$ methionine, $N=$ asparagines, $V=$ valine, $I=$ isoleucine, $D=$ aspartic acid, and $Q=$ glutamine). Below the lines are reported $A A$ substitutions that were able, alone or in combination, to gain virulence toward the va resistance alleles. B, Balance sheet of AA positions in VPg of PVYN involved in resistance breaking is also mentioned according to results reported in Tables 1 and 2.

Table 2. Biological properties of wild-type and point-mutated Potato virus $Y(\mathrm{PVY})^{\mathrm{N}}$ and $\mathrm{PVY} \mathrm{C}^{\mathrm{C}}$ infectious clones

\begin{tabular}{|c|c|c|c|c|c|c|c|c|c|c|c|c|c|c|c|c|}
\hline \multirow[b]{3}{*}{ Clone } & \multicolumn{8}{|c|}{ Tobacco genotypes and VPg sequences ${ }^{a}$} & \multicolumn{8}{|c|}{$\begin{array}{c}\text { Pairs of susceptible and resistant near-isogenic tobacco lines } \\
\text { and VPg sequences }\end{array}$} \\
\hline & \multicolumn{2}{|c|}{ MN944 (VA) } & \multicolumn{2}{|c|}{$\operatorname{VAM}\left(v a^{0}\right)$} & \multicolumn{2}{|c|}{ WISLICA $\left(v a^{I}\right)$} & \multicolumn{2}{|c|}{$\operatorname{PBD6}\left(v a^{2}\right)$} & \multicolumn{2}{|c|}{ BVA } & \multicolumn{2}{|c|}{$\operatorname{Bva0}\left(v a^{0}\right)$} & \multicolumn{2}{|c|}{ FVA } & \multicolumn{2}{|c|}{ Fva2 $\left(v a^{2}\right)$} \\
\hline & $\operatorname{Inf}^{\mathrm{c}}$ & $\mathbf{V P g}^{\mathbf{d}}$ & Inf $^{c}$ & VPgd & Inf $^{c}$ & $\mathbf{V P g}^{\mathrm{d}}$ & Inf $^{c}$ & $\mathbf{V P g}^{\mathrm{d}}$ & Inf $^{\mathrm{c}}$ & VPgd & Inf $^{\mathrm{c}}$ & VPgd & Inf $^{\mathrm{c}}$ & VPgd & Inf $^{\mathrm{c}}$ & $\mathbf{V P g}^{\mathrm{d}}$ \\
\hline $\mathrm{N} 605^{\mathrm{e}}$ & 11 & None $^{\mathrm{f}}$ & 0 & - & 5 & $\begin{array}{l}105 E \\
105 E\end{array}$ & 1 & $105 E$ & 15 & None & 1 & $105 E$ & 15 & None & 13 & $\begin{array}{l}105 E \\
105 E\end{array}$ \\
\hline N605_101G & 12 & None & 12 & $\begin{array}{l}105 N ; \\
109 D\end{array}$ & 10 & 108I; & 11 & $105 N$ & 15 & None & 15 & $\begin{array}{l}105 \mathrm{E} ; \\
109 \mathrm{~N}\end{array}$ & 15 & None & 14 & $\begin{array}{c}105 \mathrm{~N} \\
+ \\
108 \mathrm{I} \\
108 \mathrm{I}\end{array}$ \\
\hline N605_105E & 12 & $\begin{array}{c}105 \mathrm{E}+ \\
105 \mathrm{~K} \\
105 \mathrm{E}+ \\
105 \mathrm{~K}\end{array}$ & 12 & None & 12 & None & 12 & None & 15 & $\begin{array}{c}\text { None; } \\
\text { 105E + } \\
\text { 105K }\end{array}$ & 14 & None & 15 & $\begin{array}{c}105 E+ \\
105 K \\
105 E+ \\
105 K\end{array}$ & 14 & None \\
\hline N605_105T & 12 & None & 12 & None & 12 & None & 12 & None & 15 & None & 15 & None & 15 & None & 15 & None \\
\hline N605_105M & 12 & None & 12 & None & 12 & None & 12 & None & 15 & None & 14 & None & 14 & None & 14 & None \\
\hline SON $41^{\mathrm{e}}$ & 12 & None & 1 & $n d^{g}$ & 11 & $101 G$ & 9 & 101G; & 15 & None & 1 & nd & 15 & None & 10 & $101 G$ \\
\hline SON41_101G & 12 & None & 0 & - & 12 & None & 12 & None & 15 & None & 14 & $\begin{array}{l}119 N \\
120 C\end{array}$ & 13 & None & 14 & None \\
\hline SON41_119A & 12 & None & 0 & - & 10 & None & 12 & None & 15 & None & 14 & 94W; nd & 15 & None & 15 & None \\
\hline
\end{tabular}

${ }^{a}$ Tobacco genotypes used for the biological characterization: MN944 is a susceptible host; VAM, Wislica, and PBD6 are PVY-resistant host phenotypes carrying the $v a$ resistant allele 0,1 , or 2 , respectively (26).

${ }^{\mathrm{b}}$ The two pairs of near-isogenic tobacco lines are composed of a PVY-susceptible line (BVA and FVA) and a PVY-resistant line possessing, respectively, allele $0\left(\mathrm{~B} v a^{0}\right)$ or $2\left(\mathrm{~F} v a^{2}\right)$ of the $v a$ gene (27).

${ }^{c}$ Number of infected plants as assessed by DAS-ELISA 3 to 4 weeks after inoculation of 12 or 15 plants per tobacco genotype.

${ }^{\mathrm{d}} \mathrm{AA}$ variations in the VPg of viral progenies in two randomly chosen infected plants (when possible) comparatively to the inoculum. AA variations observed in the VPg of viral progenies from each of the two infected plants are listed and separated by semicolon and "+" indicates additional mutations observed in a same infected plant when compared to the original sequence of PVY isolate. AA residues are presented with the one letter code: K: lysine; N: asparagine; D: aspartic acid; E: glutamic acid; I: isoleucine; G: glycine; A: alanine; C: cysteine; and W: tryptophan

${ }^{\mathrm{e}} \mathrm{N} 605$ and SON41 are reference isolates for which a cDNA clone was available.

${ }^{\mathrm{f}}$ None: no additional AA substitutions.

$\mathrm{g} n d$ : not determined. 
toward va. Indeed, analysis of virulence patterns of N605_101G clone and the $269 \mathrm{Ch} 2$ isolate, both belonging to haplotype $\mathrm{E}^{\mathrm{N}}$, revealed that substitution $101 \mathrm{G}$ in the N605 genetic background is not sufficient to confer adaptation to at least one of the va resistance alleles. However, six PVY isolates collected from resistant tobacco plants were assigned to haplotype $\mathrm{E}^{\mathrm{N}}$ indicating that the $101 \mathrm{G}$ allows, in some viral genetic backgrounds, adaptation to some va alleles. Similar genetic background effect could also explain the different biological properties toward $v a^{0}$ and $v a^{2}$ of isolates 286 Cor 2 and 209TH8 from the $G^{\mathrm{N}}$ haplotype. The host genetic background, as described by Acosta-Leal and Xiong (2) and Montarry et al. (32), seems to modify viral adaptation capacity to resistance alleles. Experiments carried out with the avirulent N605 clone and the $v a^{0}$ (VAM and $\left.\mathrm{B} v a^{0}\right)$ or $v a^{2}$ (PBD6 and Fva $a^{2}$-derived tobacco genotypes showed that PVY infectivity in two lines carrying the same resistance allele could be quite different. The effect of the host genetic background on PVY adaptive capacity to a recessive resistance gene was already demonstrated for PVY adaptation to the recessive $p v r 2^{3}$ resistance allele in pepper (32). The effect of both virus and host genetic backgrounds for virus adaptation to a resistance gene can be explained by (i) the mechanism of action of the resistance and (ii) the biology of the viruses. Indeed, it was established that viral proteins (and, notably, the VPg) are multifunctional and that accumulation of mutations in the virus genome strongly affects virus fitness (42). The VPg of potyviruses interacts with other viral (28) and plant proteins to form functional protein networks (3). These complex virus-virus and plant-virus protein interactions could explain that VPg AA substitutions requested for virulence gain may depend on the genetic backgrounds of both host and virus. Reverse genetics carried out in this study also provided evidence that the $101 \mathrm{G}$ or 119A VPg AA substitutions were not sufficient to confer to PVY isolate SON41 adaptation to $v a^{0}$ but acquisition of these mutations increased the infectivity on $v a^{0}$ resistant genotypes compared with the original SON41 clone. Similarly, although the $101 \mathrm{G}$ substitution introduced into N605 was not sufficient to confer $\mathrm{PVY}^{\mathrm{N}}$ virulence to $v a^{0}$, the presence of this substitution in the PVY-N605 genetic background promotes the adaptation of $\mathrm{PVY}^{\mathrm{N}}$ to $v a^{0}$ by accumulating additional AA substitutions to efficiently infect $v a^{0}$ plants.

Mutations in VPg have already been associated with recessive resistance-breaking capacity for potyviruses (9) and for different plant virus genera $(16,25)$. Ayme et al. (5) have shown that eight AAs of the central part of the PVY VPg were associated with the resistance-breaking phenotype for alleles of the $p v r 2$ gene in the PVY-pepper pathosystem (5). Actually, the central domain of the VPg was predicted to include an amphiphilic $\alpha$-helix (38), and six (including residues 101 and 119) of the eight AA positions previously described to be involved in PVY-VPg interaction are located on one side of the helix. This suggests that similar mechanisms are involved in the resistance-breaking process in PVY-tobacco $(v a)$ and PVY-pepper ( $p v r 2)$. It was demonstrated that $p v r 2$ codes for the translation initiation factor $4 \mathrm{E}$ (eIF4E), known to be involved in genome replication of potyviruses (40). In addition to its functions in translation initiation, it was demonstrated that the eIF4E was also involved in cell-to-cell movement of viral particles (12). The possibility that $v a$ corresponds to eIF4E, as suggested by Lacroix et al. (27) and Acosta-Leal and Xiong (2), is strengthened.

Finally, it would be worth examining the properties of the SON41_101G clone. In PVY, mutation-selection balance was observed between the fixation of AA substitutions in the coat protein of the virus and the PVY ${ }^{\mathrm{N}}$ fitness in potato or tobacco (36). Regarding PVY infectivity in tobacco and pepper resistant genotypes, we showed that the $101 \mathrm{G}$ substitution in the VPg of SON41 conferred adaptation to the $v a^{1}$ and $v a^{2}$ resistance alleles in tobacco. Moreover, it was already reported that the VPg-101G substitution in SON41 genetic background confers virulence toward the $p v r 2^{3}$ (eIF4E) resistance allele in pepper (6). These observations constitute a rare case of cross-virulence (17) or exaptation (29) for plant viruses and strengthen the possibility that $v a$ corresponds to eIF4E, as suggested by Lacroix et al. (27) and Acosta-Leal and Xiong (2).
From an agronomic point of view, the cross-virulence property toward resistances in two different hosts for a given pathogen is an important characteristic to take into account for the deployment and management of plant resistance sources.

This work highlighted the fact that PVY-avirulent populations were able to adapt to $v a$ resistance after the infection of a single resistant plant via evolutionary pathways that required AA substitutions at specific positions in VPg. To ensure a fair deployment of the $v a$-mediated resistance in a tobacco-growing area, it seems worthwhile to explore its prevalence in a PVY population of isolates in each PVY group because evolution to gain virulence toward $v a$ seems different according to the PVY groups. In most cases, adaptation to $v a$ corresponds to a single nonsynonymous nucleotide substitution in the PVY VPg cistron that changed $\mathrm{AA}_{105}$. This mutational pathway confers virulence toward the three va resistance alleles. However, depending on virus and host genetic backgrounds, other evolutionary pathways could allow, to a lesser extent, adaptation to $v a$. Exploring the presence in the grown fields of $\mathrm{PVY}^{\mathrm{N}}$ and $\mathrm{PVY}^{\mathrm{O}}$ isolates already adapted to $v a$ through $105-$ VPg mutations is also a critical point. Because VPg $\mathrm{AA}_{105}$ mutations can confer adaptation to all $v a$ alleles, the presence of resistance-breaking isolates harboring $\mathrm{AA}_{105}$ adaptive mutation in fields could made ineffective strategies aiming to replace $v a$ alleles in the tobacco genotypes already deployed. Finally, concurrent growth of resistant pepper and tobacco should be avoided because the selective pressure imposed by the $p v r 2$ resistance gene in pepper could promote the selection of $\mathrm{PVY}^{\mathrm{C}}$ isolates adapted to $v a$.

Studies focusing on plant virus adaptation to resistance reported that the smaller the number of substitutions required for virulence, the lower the durability of the corresponding resistance $(19,34)$. Taking into account data presented in this article, we assume a low durability for the $v a$ resistance alleles. However, gains of virulence toward resistant genotypes are frequently associated with fitness costs in susceptible genotypes $(11,19)$. Thus, the fitness cost imposed by each adaptive substitution should be explored to determine possible consequences on the maintenance of resistancebreaking isolates in natural PVY populations. The observation in a susceptible tobacco line of reverting mutations in some resistancebreaking isolates suggests that $v a$-adaptive mutations have a cost on PVY fitness (Table 1). Despite the fact that no data related to fitness cost imposed by the different adaptive mutations were collected in this study, and taking into account results published by Acosta-Leal and Xiong $(1,2)$ on PVY-va-derived tobacco genotypes, the evolutionary pathways leading to the fixation of adaptive substitutions in the VPg sequence seem to be regulated by genetic constraints linked to host-virus interactions. Upcoming analysis on the impact of each $v a$-adaptive substitution on PVY fitness should teach us whether isolates virulent toward $v a$ could be maintained in a natural PVY population and whether strategies that reduce the selective pressure imposed by $v a$ resistance should be considered to counterbalance selection in a PVY population of $v a$-resistancebreaking isolates.

\section{Acknowledgments}

This work has been realized at the Institut National de la Recherche Agronomique (INRA, France) and has obtained the financial support of the Imperial Tobacco Group and the Association for Research on Nicotianae (ARN).

\section{Literature Cited}

1. Acosta-Leal, R., and Xiong, Z. 2008. Complementary functions of two recessive R-genes determine resistance durability of tobacco Virgin A Mutant (VAM) to Potato virus Y. Virology 379:275-283.

2. Acosta-Leal, R., and Xiong, Z. 2013. Intrahost mechanisms governing emergence of resistance-breaking variants of Potato virus $Y$. Virology 437:39-47.

3. Ala-Poikela, M., Goytia, E., Haikonen, T., Rajamaki, M. L., and Valkonen, J. P. T. 2011. Helper component proteinase of the genus Potyvirus is an interaction partner of translation initiation factors eIF(iso)4E and eIF4E and contains a 4E binding motif. J. Virol. 85:6784-6794.

4. Ano, G., Blancard, D., and Cailleteau, B. 1995. Mise au point sur la résistance récessive aux souches nécrotiques du virus $\mathrm{Y}$ de la pomme de terre (PVY) présente chez Nicotiana tabacum. Ann. Tabac 27:35-42.

5. Ayme, V., Petit-Pierre, J., Souche, S., Palloix, A., and Moury, B. 2007. Mo- 
lecular dissection of the Potato virus $Y$ VPg virulence factor reveals complex adaptations to the $p v r 2$ resistance allelic series in pepper. J. Gen. Virol. 88:1594-1601.

6. Ayme, V., Souche, S., Caranta, C., Jacquemond, M., Chadoeuf, J., Palloix, A., and Moury, B. 2006. Different mutations in the genome-linked protein VPg of Potato virus $Y$ confer virulence on the $p v r 2(3)$ resistance in pepper. Mol. Plant-Microbe Interact. 19:557-563.

7. Blancard, D., Ano, G., and Cailleteau, B. 1995. Etude du pouvoir pathogène d'isolats de PVY sur tabac: Proposition d'une classification intégrant la résistance à la nécrose. Ann. Tabac 27:43-50.

8. Blanchard, A., Rolland, M., Lacroix, C., Kerlan, C., and Jacquot, E. 2008. Potato virus Y: A century of evolution. Curr. Top. Virol. 7:21-32.

9. Bruun-Rasmussen, M., Moller, I. S., Tulinius, G., Hansen, J. K. R., Lund, O. S., and Johansen, I. E. 2007. The same allele of translation initiation factor 4E mediates resistance against two Potyvirus spp. in Pisum sativum. Mol. Plant-Microbe Interact. 20:1075-1082.

10. Chain, F., Riault, G., Trottet, M., and Jacquot, E. 2007. Evaluation of the durability of the Barley yellow dwarf virus-resistant Zhong ZH and TC14 wheat lines. Eur. J. Plant Pathol. 117:35-43.

11. Fabre, F., Rousseau, E., Mailleret, L., and Moury, B. 2012. Durable strategies to deploy plant resistance in agricultural landscapes. New Phytol. 193:1064-1075.

12. Gao, Z. H., Johansen, E., Eyers, S., Thomas, C. L., Noel Ellis, T. H., and Maule, A. J. 2004. The Potyvirus recessive resistance gene, sbm1, identifies a novel role for translation initiation factor eIF4E in cell-to-cell trafficking. Plant J. 40:376-385.

13. Garcia-Arenal, F., and McDonald, B. A. 2003. An analysis of the durability of resistance to plant viruses. Phytopathology 93:941-952.

14. Gebre-Selassie, K., Marchoux, G., Delecolle, B., and Pochard, E. 1985. Variabilité naturelle des souches du virus Y de la pomme de terre dans les cultures de piment du sud-est de la France. Caractérisation et classification en pathotypes. Agronomie 5:621-630.

15. Gooding, G. V., and Tolin, S. A. 1973. Strains of Potato Virus Y Affecting Flue-Cured Tobacco in Southeastern United-States. Plant Dis. Rep. 57:200204.

16. Hébrard, E., Pinel-Galzi, A., Bersoult, A., Sire, C., and Fargette, D. 2006. Emergence of a resistance-breaking isolate of Rice yellow mottle virus during serial inoculations is due to a single substitution in the genome-linked viral protein VPg. J. Gen. Virol. 87:1369-1373.

17. Heinrichs, E. A., and Rapusas, H. R. 1985. Cross-Virulence of Nephotettixvirescens (Homoptera, Cicadellidae) biotypes among some rice cultivars with the same major-resistance gene. Environ. Entomol. 14:696-700.

18. Jakab, G., Droz, E., Brigneti, G., Baulcombe, D., and Malnoe, P. 1997. Infectious in vivo and in vitro transcripts from a full-length cDNA clone of PVY-N605, a Swiss necrotic isolate of Potato virus Y. J. Gen. Virol. 78:3141-3145

19. Janzac, B., Fabre, F., Palloix, A., and Moury, B. 2009. Constraints on evolution of virus avirulence factors predict the durability of corresponding plant resistances. Mol. Plant Pathol. 10:599-610.

20. Johansen, I. E., Lund, O. S., Hjulsager, C. K., and Laursen, J. 2001. Recessive resistance in Pisum sativum and potyvirus pathotype resolved in a gene-for-cistron correspondence between host and virus. J. Virol. 75:66096614.

21. Jones, D. T., Taylor, W. R., and Thornton, J. M. 1992. The rapid generation of mutation data matrices from protein sequences. Comput. Appl. Biosci. $8: 275-282$

22. Karasev, A. V., Nikolaeva, O. V., Hu, X., Sielaff, Z., Whitworth, J., Lorenzen, J. H., and Gray, S. M. 2010. Serological properties of ordinary and necrotic isolates of Potato virus $Y$ : A case study of $\mathrm{PVY}^{\mathrm{N}}$ misidentification. American J. Potato Res. 87:1-9.

23. Kerlan, C., and Moury, B. 2008. Potato virus Y. Pages 287-296 in: Encyclopedia of Virology. B. W. J. Mahy and M. H. V. Van Regenmortel, eds. Elsevier, Oxford

24. Kosakovsky Pond, S. L., Frost, S. D. W., and Muse, S. V. 2005. HyPhy: Hypothesis testing using phylogenies. Bioinformatics 21:676-679.

25. Kühne, T., Shi, N., Proeseler, G., Adams, M. J., and Kanyuka, K. 2003. The ability of a bymovirus to overcome the rym4-mediated resistance in barley correlates with a codon change in the VPg coding region on RNA1. J. Gen. Virol. 84:2853-2859.

26. Lacroix, C., Glais, L., Kerlan, C., Verrier, J. L., and Jacquot, E. 2010. Biological characterization of French Potato virus $Y$ (PVY) isolates collected from PVY-susceptible or -resistant tobacco plants possessing the recessive resistance gene va. Plant Pathol. 59:1133-1143.
27. Lacroix, C., Glais, L., Verrier, J. L., and Jacquot, E. 2011. Effect of passage of a Potato virus $Y$ isolate on a line of tobacco containing the recessive resistance gene $v a(2)$ on the development of isolates capable of overcoming alleles 0 and 2. Eur. J. Plant Pathol. 130:259-269.

28. Lin, L., Shi, Y. H., Luo, Z. P., Lu, Y. W., Zheng, H. Y., Yan, F., Chen, J., Chen, J. P., Adams, M. J., and Wu, Y. F. 2009. Protein-protein interactions in two potyviruses using the yeast two-hybrid system. Virus Res. 142:36-40.

29. Losos, J. B. 2011. Convergence, adaptation, and constraint. Evolution 65:1827-1840.

30. Masuta, C., Nishimura, M., Morishita, H., and Hataya, T. 1999. A single amino acid change in viral genome-associated protein of Potato virus $Y$ correlates with resistance breaking in 'Virgin A Mutant' tobacco. Phytopathology 89:118-123.

31. McDonald, B. A., and Linde, C. 2002. Pathogen population genetics, evolutionary potential, and durable resistance. Annu. Rev. Phytopathol. 40:349379.

32. Montarry, J., Doumayrou, J., Simon, V., and Moury, B. 2011. Genetic background matters: A plant-virus gene-for-gene interaction is strongly influenced by genetic contexts. Mol. Plant Pathol. 12:911-920.

33. Moury, B. 2010. A new lineage sheds light on the evolutionary history of Potato virus Y. Mol. Plant Pathol. 11:161-168.

34. Moury, B., Fabre, F., Montarry, J., Janzac, B., Ayme, V., and Palloix, A. 2010. The adaptation of plant viruses to varietal resistances. Virologie 14:227-239.

35. Moury, B., Morel, C., Johansen, E., Guilbaud, L., Souche, S., Ayme, V., Caranta, C., Palloix, A., and Jacquemond, M. 2004. Mutations in Potato virus $Y$ genome-linked protein determine virulence toward recessive resistances in Capsicum annuum and Lycopersicon hirsutum. Mol. PlantMicrobe Interact. 17:322-329.

36. Moury, B., and Simon, V. 2011. dN/dS-based methods detect positive selection linked to trade-offs between different fitness traits in the coat protein of Potato virus Y. Mol. Biol. Evol. 28:2707-2717.

37. Quenouille, J., Vassilakos, N., and Moury, B. 2013. Potato virus Y: A major crop pathogen that has provided major insights into the evolution of viral pathogenicity. Mol. Plant Pathol. 14:439-452.

38. Roudet-Tavert, G., Michon, T., Walter, J., Delaunay, T., Redondo, E., and Le Gall, O. 2007. Central domain of a potyvirus VPg is involved in the interaction with the host translation initiation factor eIF4E and the viral protein HcPro. J. Gen. Virol. 88:1029-1033.

39. Robaglia, C., and Caranta, C. 2006. Translation initiation factors: A weak link in plant RNA virus infection. Trends Plant Sci. 11:40-45.

40. Ruffel, S., Dussault, M. H., Palloix, A., Moury, B., Bendahmane, A., Robaglia, C., and Caranta, C. 2002. A natural recessive resistance gene against Potato virus $Y$ in pepper corresponds to the eukaryotic initiation factor $4 \mathrm{E}$ (eIF4E). Plant J. 32:1067-1075.

41. Rufty, R. C., Powell, N. T., and Gooding, G. V. 1983. Relationship between resistance to Meloidogyne incognita and a necrotic response to infection by a strain of Potato virus Y in tobacco. Phytopathology 73:1418-1423.

42. Sanjuán, R., Moya, A., and Elena, S. F. 2004. The distribution of fitness effects caused by single-nucleotide substitutions in an RNA virus. Proc. Natl. Acad. Sci. USA 101:8396-8401.

43. Scholthof, K. B. G., Adkins, S., Czosnek, H., Palukaitis, P., Jacquot, E., Hohn, T., Hohn, B., Saunders, K., Candresse, T., Ahlquist, P., Hemenway, C., and Foster, G. D. 2011. Top 10 plant viruses in molecular plant pathology. Mol. Plant Pathol. 12:938-954.

44. Singh, M., and Singh, R. P. 1996. Nucleotide sequence and genome organization of a Canadian isolate of the common strain of Potato virus $Y$ $\left(\mathrm{PVY}^{\mathrm{O}}\right)$. Can. J. Plant Pathol. 18:209-224

45. Singh, R. P., Valkonen, J. P. T., Gray, S. M., Boonham, N., Jones, R. A. C. Kerlan, C., and Schubert, J. 2008. Discussion paper: The naming of Potato virus $Y$ strains infecting potato. Arch. Virol. 153:1-13.

46. Tamura, K., Peterson, D., Peterson, N., Stecher, G., Nei, M., and Kumar, S 2011. MEGA5: Molecular evolutionary genetics analysis using maximum likelihood, evolutionary distance, and maximum parsimony methods. Mol. Biol. Evol. 28:2731-2739.

47. Tribodet, M., Glais, L., Kerlan, C., and Jacquot, E. 2005. Characterization of Potato virus $Y$ (PVY) molecular determinants involved in the vein necrosis symptom induced by $\mathrm{PVY}^{\mathrm{N}}$ isolates in infected Nicotiana tabacum $\mathrm{cv}$ Xanthi. J. Gen. Virol. 86:2101-2105.

48. Verrier, J. L., and Doroszewska, T. 2004. The " $v a$ " resistance to $\mathrm{PVY}^{\mathrm{N}}$ in Nicotiana tabacum: An assessment of the frequency of " $v a$ " breaking PVY strains based on seven years of field survey on a worldwide basis. Abstract in: Proc. 12th Eur. Assoc. Potato Res. (Virol. Sect.) Meet. Rennes, France. 